\title{
Evaluating the mitochondrial function
}

\author{
Emin Ozgur Akgul ${ }^{1 *}$, Mehmet Toygar ${ }^{2}$ and Yavuz Poyrazoglu ${ }^{3}$
}

\section{Dear Editor}

We have read the article by Xia et.al. entitled as "L-carnitine ameliorated fatty liver in high-calorie diet/ STZ induced type 2 diabetic mice by improving mitochondrial function" with great interest [1]. In this article, the authors concluded that L-carnitine might be an effective liver cell protector for delaying the progression of type 2 diabetes mellitus complications. They supported this conclusion by using biochemical and morphological differences between control and L-carnitine-treated groups. However, we have some reservations the terms they used throughout the article: Firstly, the term of "mitochondrial function" has a very broad meaning and might be a little bit confusing as well. As known, mitochondria basically have three biochemical systems: i) $\beta$-oxidation, ii) tricarboxylic acid cycle (TCA cycle) and iii) electron transport chain. Although all these systems are interconnected and coexist in mitochondria at the same time, only dysfunctions of electron transport chain are enumerated among the mitochondrial diseases. In this article, we understand that the mitochondrial complex activities were not measured at all. Therefore, we think that the conclusion saying "L-carnitine stimulates fat metabolism" is acceptable. But, using the term of "improvement of mitochondrial function" in this context is not scientifically very appropriate. Secondly, the authors did not describe the method(s) they used in "morphological assessment of hepatic tissue" in detail. They said that tissue samples have been fixed in $4 \%$ paraformaldehyde in the third page of the paper. But, as far as we know, oil red O staining works only with fresh frozen tissues. Besides, the red dots in figure 2 were presented as lipid droplets. If these are lipid droplets, then the other unstained vacuoles in the same figure were remained to be identified. We think that the tissues stained with oil red $\mathrm{O}$ must be fresh-frozen samples, and at least some of that unstained vacuoles were actually freezing

\footnotetext{
* Correspondence: eoakgul@yahoo.com

'Department of Clinical Chemistry, Gulhane School Of Medicine, Ankara, Turkey

Full list of author information is available at the end of the article
}

artifacts. Discrimination between freezing artifacts and lipid vacuoles are important because the authors assumed that L-carnitine was decreasing "lipid area percentage" in hepatic tissue.

\section{Author details}

'Department of Clinical Chemistry, Gulhane School Of Medicine, Ankara, Turkey. ${ }^{2}$ Department of Forensic Medicine, Gulhane School Of Medicine, Ankara, Turkey. ${ }^{3}$ Department of General Surgery, Gulhane School Of Medicine, Ankara, Turkey.

\section{Authors' contributions}

Dr. EO AKGUL, MD is the corresponding author of this letter. He evaluated that paper from biochemical aspect. Dr MT, MD is specialist of forensic medicine. He evaluated that paper form morphological aspect. Dr. YP is specialist of general surgery. He drafted the letter. All authors read and approved the final manuscript.

\section{Competing interests}

The authors declare that they have no competing interests.

Received: 28 January 2012 Accepted: 4 April 2012

Published: 4 April 2012

\section{Reference}

1. Xia Y, Li Q, Zhong W, Dong J, Wang Z, Wang C: L-carnitine ameliorated fatty liver in high-calorie diet/STZ-induced type 2 diabetic mice by improving mitochondrial function. Diabetol Metab Syndr 2011, 3:31.

doi:10.1186/1758-5996-4-11

Cite this article as: Akgul et al:: Evaluating the mitochondrial function. Diabetology \& Metabolic Syndrome 2012 4:11.

\section{Submit your next manuscript to BioMed Central} and take full advantage of:

\section{- Convenient online submission}

- Thorough peer review

- No space constraints or color figure charges

- Immediate publication on acceptance

- Inclusion in PubMed, CAS, Scopus and Google Scholar

- Research which is freely available for redistribution

\section{Biomed Central}

